\title{
Metformin inhibits ovarian cancer via decreasing H3K27 trimethylation
}

\author{
GUIJU TANG, JIANFENG GUO, YAPEI ZHU, ZAIJU HUANG, TING LIU, JING CAI, LILI YU and ZEHUA WANG
}

\author{
Department of Obstetrics and Gynecology, Union Hospital, Tongji Medical College, \\ Huazhong University of Science and Technology, Wuhan, Hubei 430022, P.R. China
}

Received November 23, 2017; Accepted March 19, 2018

DOI: $10.3892 /$ ijo.2018.4343

\begin{abstract}
Metformin has been used for the treatment of type II diabetes mellitus for decades. Recently, used of metformin in the therapy of diverse human cancer types has received widespread attention, while the underlying mechanisms have been not fully elucidated. In the current study, 5-ethynyl-20-deoxyuridine assay to detect cell proliferation, flow cytometry to detect apoptosis, scratch wound healing and Transwell migration assay to detect cell migration capacity. The current study reported that metformin inhibited cell proliferation and migration, and promoted apoptosis in ovarian cancer cells, particularly under normoglycemic conditions in vitro. Metformin treatment significantly promoted the phosphorylation of AMP-activated protein kinase (AMPK), and reduced histone $\mathrm{H} 3$ lysine 27 trimethylation (H3K27me3) and polycomb repressor complex 2 (PRC2) levels. Additionally, overexpression of EZH2 to increase H3K27me3 abrogated the effect of metformin on the cell proliferation, migration and apoptosis in SKOV3 and ES2 cells. Similar to metformin, another AMPK agonist, 2-deoxy-D-glucose, reduced the H3K27me3 level and PRC2 expression. In cells pretreated with Compound $\mathrm{C}$, an AMPK inhibitor, metformin was not able to induce AMPK phosphorylation or reduce $\mathrm{H} 3 \mathrm{~K} 27 \mathrm{me} 3$. Metformin-mediated AMPK activation and H3K27me3 inhibition were more robust in cells exposed to low glucose $(5.5 \mathrm{mM})$ compared with those exposed to high glucose $(25 \mathrm{mM})$. These findings implicate H3K27me3 repression mediated by AMPK phosphorylation in the antitumor effect of metformin in ovarian cancer, indicating that metformin alters epigenetic modifications by targeting PRC2 and supports the use of metformin in treatment of patients with epithelial ovarian cancer without diabetes.
\end{abstract}

Correspondence to: Professor Zehua Wang, Department of Obstetrics and Gynecology, Union Hospital, Tongji Medical College, Huazhong University of Science and Technology, 1277 Jiefang Avenue, Wuhan, Hubei 430022, P.R. China

E-mail: zehuawang@163.net

Key words: metformin, histone H3 lysine 27 trimethylation, polycomb repressor complex 2, AMP-activated protein kinase, ovarian cancer

\section{Introduction}

Ovarian cancer is the most lethal gynecologic malignancy and the fifth leading cause for cancer mortality among women in the United States (1). A reason for this high mortality is chemotherapeutic resistance, as recurrent and metastatic ovarian cancer usually exhibits resistant to platinum-based chemotherapy (2). Thus, there is an urgent need to identify novel drugs for use in ovarian cancer therapy.

Metformin (1,1-dimethylbiguanide), an oral biguanide first introduced in the 1950s, has been used as the first-line medication for the treatment of type II diabetes mellitus for decades. Recently metformin has gained renewed interest as a potential cancer chemotherapy adjuvant in adjuvant or neoadjuvant setting $(3,4)$. Numerous studies have demonstrated antitumor effects of metformin in vitro and in vivo using models using different types of cancer cell lines, including breast, endometrial and ovarian cancer cell lines (5-7). Furthermore, clinical observational studies demonstrated that patients with ovarian cancer exposed to metformin had reduced disease recurrences and cancer-specific mortalities compared with unexposed women (8-10). A phase II clinical trial to assess whether the addition of metformin to standard chemotherapy improves survival in non-diabetic ovarian cancer patients is ongoing (NCT02122185; clinicaltrials.gov).

Although metformin has been used as an anti-diabetic agent for over half a century, its molecular mechanisms are still not fully understood. The most described mechanism of metformin is inhibition of mitochondrial respiratory chain complex I, leading to reduced ATP production and activation of AMP-activated protein kinase (AMPK), which in turn leads to increased glucose uptake by muscle, decreased glucose production in liver, and reduced blood glucose (11). In cancer cells, AMPK is considered a tumor-suppressing pathway, which inhibits the mammalian target of the rapamycin signaling, suppresses cell proliferation, and promotes apoptosis and cell-cycle arrest $(12,13)$. AMPK-independent effects of metformin in cancer, such as the inhibition of protein kinase phosphorylation in breast and lung cancers, have been also reported (14). However, whether metformin inhibits ovarian cancer via the AMPK pathway and underlying downstream molecular mechanisms remains elusive.

Epigenetic modifications, including DNA methylation of the $\mathrm{CpG}$ sites, and covalent modifications of the $\mathrm{N}$-terminal 
tail of the core histones, have critical roles in tumor development and progression (15). Histone H3 lysine 27 trimethylation (H3K27me3) is recognized as an epigenetic marker in malignancies, because H3K27me3 reprograms epigenetic landscape and gene expression, which is associated with various pathways to drive tumorigenesis (16). In ovarian cancer, $\mathrm{H} 3 \mathrm{~K} 27 \mathrm{me} 3$ contributes to the formation of the tumor microenvironment (17), the development of resistance to cisplatin and tumor progression (18). H3K27me3 is catalyzed by histone-lysine N-methyltransferase EZH2 that interacts with polycomb protein SUZ12 and polycomb protein EED as polycomb repressive complex 2 (PRC2) and mediates gene silencing through promoter methylation and chromatin remodeling (19). EZH2 depletion and H3K27me3 inhibition in ovarian cancer cells could inhibit tumor growth, migration, and invasion, and enhance sensitized tumor cells to cisplatin in vitro and in vivo $(20,21)$. Notably, EZH2 and H3K27me3 have been reported to contribute to the development of renal injury and chronic inflammation in type 2 diabetes $(22,23)$, demonstrating the role of H3K27me3 in energy stress.

In the present study, it was aimed to investigate whether metformin inhibits ovarian cancer through repressing H3K27me3. Given that metformin is predominantly used to treat patients with type II diabetes and high glucose concentration inhibits the activation of AMPK (24), the role of glucose concentration in the effects of metformin in ovarian cancer cells was also examined.

\section{Materials and methods}

Chemical, reagents and antibodies. The following chemicals were used in the current study. Metformin (1,1-dimethylbiguanide,) was purchased from Sigma-Aldrich (Merck KGaA, Darmstadt, Germany; cat. no. 150959). 2-Deoxy-D-glucose (2-DG; cat. no. S4701) and dorsomorphin $2 \mathrm{HCl}$ (Compound C) (cat. no. S7306) were purchased from Selleck Chemicals (Houston, TX, USA). Antibodies against phospho-AMPK $\alpha$ (p-AMPK $\alpha$, Thr172; cat. no. 2535), AMPK $\alpha$ (cat. no. 2603), EZH2 (cat. no. 5246), SUZ12 (cat. no. 3737) were purchased from Cell Signaling Technology, Inc. (Danvers, MA, USA). Histone H3 (cat. no. 2348), H3K27me3 (cat. no. 2363), EED (cat. no. 5371) antibodies were purchased from ABclonal Biotech Co., Ltd. (Woburn, MA, USA). $\beta$-actin antibody (cat. no. 66009-1-Ig) was purchased from Proteintech, Inc. (Chicago, IL, USA). Horseradish peroxidase-conjugated (HRP) anti-mouse antibody (cat. no. 074-1806-1) and HRP anti-rabbit antibody (cat. no. 074-1506-1) were purchased from KPL, Inc. (Gaithersburg, MD, USA).

Cell lines and culture conditions. Human epithelial ovarian cancer cell lines SKOV3 (ovarian adenocarcinoma), ES2 (ovarian clear cell carcinoma), and A2780 (ovarian carcinoma) were purchased from China Center for Type Culture Collection (Wuhan University, Wuhan, China) and were cultured in Dulbecco's modified Eagle's medium (DMEM) (HyClone; GE Healthcare Life Sciences, Logan, UT, USA) containing $25 \mathrm{mM}$ glucose (mimicking hyperglycemia) or $5.5 \mathrm{mM}$ glucose (mimicking normoglycemia) supplemented with $10 \%$ fetal bovine serum (v/v; Hangzhou Sijiqing Biological Engineering Materials Co., Ltd., Hangzhou, China) at $37^{\circ} \mathrm{C}$ in $95 \%$ air and $5 \% \mathrm{CO}_{2}$.
For metformin treatment, ovarian cancer cells were seeded at a density of $4 \times 10^{5}$ per well on 6-well plates and incubated for $24 \mathrm{~h}$. Then they were treated with metformin of different concentrations $(0,2.5,5$ or $10 \mathrm{mM})$ for $24 \mathrm{~h}$ in triplicate. 2-DG, an AMPK activator, was used to induce AMPK phosphorylation in tumor cells, whereby cells were treated with $25 \mathrm{mM}$ 2-DG for $24 \mathrm{~h}$. To inhibit the metformin-mediated AMPK activation, cells were pretreated with $20 \mu \mathrm{M}$ Compound $\mathrm{C}$ for $2 \mathrm{~h}$ followed by treatment with $5 \mathrm{mM}$ metformin for $24 \mathrm{~h}$.

Transduction in vitro. A recombinant lentivirus harboring EZH2 DNA (NM_004456; GeneChem Co., Ltd., Shanghai, China) was used to upregulate the EZH2 level in the SKOV3 and ES2 cells. An empty vector (Con307; GeneChem Co., Ltd.) was used as control. Stable transduction was conducted following the manufacturers' instructions. Transduction cells were selected with $25 \mu \mathrm{g} / \mathrm{ml}$ puromycin and monoclonal cells were used for subsequent experiments. The transfection efficiency was confirmed by western blot analysis.

Proliferation assay. 5-Ethynyl-20-deoxyuridine (EdU) DNA cell proliferation kits were purchased from Guangzhou RiboBio Co., Ltd. (Guangzhou, China). Cell proliferation activity was evaluated according to the manufacturer's instructions. Briefly, ovarian cancer cells were seeded in triplicate at a density of $5 \times 10^{3}$ cells/well in 96 -well plates. After $24 \mathrm{~h}$, cells were washed with PBS twice and fixed with $4 \%$ formaldehyde at room temperature for $30 \mathrm{~min}$. Subsequently, the cells were treated with $0.5 \%$ Triton X-100 for 10 min at room temperature for permeabilization, followed by incubation with EdU at room temperature for $1 \mathrm{~h}$. Finally, the cells were counterstained with $5 \mu \mathrm{g} / \mathrm{ml}$ Hoechst 33342 at room temperature for $30 \mathrm{~min}$. The proportion of EdU-incorporated cells was defined as the proliferation rate. The assay was performed in three biological replicates.

Analysis of cell apoptosis via flow cytometry. The effects of metformin on ovarian cancer cell apoptosis were assessed by flow cytometry using Annexin V-fluorescein isothiocyanate (FITC)/propidium iodide (PI) staining kit (BD Pharmingen; BDBiosciences, San Jose, CA,USA). Ascells transduced with lentiviruscarried green fluorescence, their apoptosis rates were assessed by using Annexin V-phycoerythrin (PE)/7-aminoactinomycin D (7-AAD) staining kit (BD Pharmingen; BD Biosciences). After $24 \mathrm{~h}$ of exposure to metformin, cells were washed twice with ice-cold PBS, re-suspended in $500 \mu \mathrm{l}$ binding buffer, and stained with $5 \mu \mathrm{l}$ FITC-conjugated $5 \mu \mathrm{l}$ Annexin V or $5 \mu \mathrm{l}$ Annexin V-PE conjugated and $7 \mu 1$ 7-AAD, following gentle mixing, cells were incubated at room temperature shielded from light for $15 \mathrm{~min}$. Following washing with binding buffer, flow cytometry analysis was performed using a flow cytometry sorting system (MoFlo XDP) with Summit 6.2 software (both from Beckman Coulter, Inc., Brea, CA, USA). Each assay was run at least three times.

Scratch wound healing assay. Cells were seeded into 6-well plates at a destiny of $6 \times 10^{5}$ cells/well. Following incubation overnight, a scratch wound was introduced on the cell monolayer using a $100 \mu \mathrm{l}$ pipette tip. PBS was used to wash away the floating cells and then cultured in serum-free growth media. The migration of cells into the wound area was observed at $0 \mathrm{~h}$ 
Table I. Primer sequences used for reverse transcription-quantitative polymerase chain reaction.

\begin{tabular}{lll}
\hline Primer & \multicolumn{1}{c}{ Forward (5'-3') } & \multicolumn{1}{c}{ Reverse (5'-3') } \\
\hline EZH2 & TTGTTGGCGGAAGCGTGTAAAATC & TCCCTAGTCCCGCGCAATGAGC \\
SUZ12 & GCATTGCCCTTGGTGTACTC & TGGTCCGTTGCGACTAAAA \\
EED & ATGCTGTCAGTATTGAGAGTGGC & GAGGCTGTTCACACATTTGAAAG \\
$\beta$-actin & GCCAACACAGTGCTGTCTGG & GCTCAGGAGGAGCAATGATCTTG
\end{tabular}

EZH2, histone-lysine N-methyltransferase EZH2; SUZ12, polycomb protein SUZ12; EED, polycomb protein EED.

and $24 \mathrm{~h}$. For quantification, the wound gap was imaged using a light microscope (Olympus Corporation, Tokyo, Japan), then measured using Image-Pro Plus 6.0 (Media Cybernetics, Inc., Rockville, MD, USA) and the mean recovery gaps were to normalized $0 \mathrm{~h}$. Each assay was performed at least three times.

Transwell migration assay. Transwell chambers (6.5-mm diameter; 24-well) were used for migration assays (Costar; Corning Incorporated, Corning, NY, USA). SKOV3 $\left(5 \times 10^{4}\right.$ cells $\left./ \mathrm{ml}\right)$, ES2 $\left(5 \times 10^{4}\right.$ cells $\left./ \mathrm{ml}\right)$, A2780 $\left(8 \times 10^{4}\right.$ cells $\left./ \mathrm{ml}\right)$ in $100 \mu 1$ serumfree DMEM were seeded in each Transwell insert. The lower chamber was contained $650 \mu 1$ DMEM medium supplemented with $20 \%$ fetal bovine serum. After incubation at $37^{\circ} \mathrm{C}$ for $24 \mathrm{~h}$, non-migrated cells on the upper membrane surface were wiped with a cotton swab. Cells that had migrated to the lower surfaces of each filter were fixed with $4 \%$ paraformaldehyde for 30 min and stained with $0.1 \%$ crystal violet at room temperature for $1 \mathrm{~h}$. Then, cells were counted in five randomly selected visual fields under a light microscope (Olympus Corporation). Each assay was performed at least three times.

Reverse transcription-quantitative polymerase chain reaction $(R T-q P C R)$. Total RNA was isolated and extracted using TRIzol $^{\circledR}$ reagent (Thermo Fisher Scientific, Inc., Waltham, MA, USA) according to the manufacturer's instructions, and $1 \mu \mathrm{g}$ total RNA in a final volume of $20 \mu \mathrm{l}$ was used for RT with PrimeScript RT Master Mix Kit (Takara Bio, Inc., Otsu, Japan). Reverse transcription reaction was performed under the following conditions: $37^{\circ} \mathrm{C}$ for $15 \mathrm{~min}, 85^{\circ} \mathrm{C}$ for $5 \mathrm{sec}, 4^{\circ} \mathrm{C}$ for $5 \mathrm{~min}$. PCR reaction system included $10 \mu \mathrm{l}$ Eva Green Mix, $1 \mu \mathrm{l} \mathrm{cDNA}, 10 \mu \mathrm{M}$ forward primer, $10 \mu \mathrm{M}$ reverse primer, with $\mathrm{ddH}_{2} \mathrm{O}$ up to $20 \mu \mathrm{l}$. The mRNA was quantitated using a TaqMan One Step Gold RT-PCR kit (Applied Biosystems; Thermo Fisher Scientific, Inc.). qPCR was performed under the following conditions: 40 cycles at $95^{\circ} \mathrm{C}$ for $5 \mathrm{sec}$ and $60^{\circ} \mathrm{C}$ for $30 \mathrm{sec}\left(\mathrm{EZH} 2, \mathrm{SUZ1} 2\right.$ and $\beta$-actin); 40 cycles at $95^{\circ} \mathrm{C}$ for $5 \mathrm{sec}$ and $52^{\circ} \mathrm{C}$ for $30 \mathrm{sec}$ (EED). Primer sequences are shown in Table I. The relative expression levels of EZH2, SUZ12 and EED to $\beta$-actin were calculated using the $2^{-\Delta \Delta \mathrm{Cq}}$ method (25). All reactions were in triplicate and at least three biological replicated were assessed.

Western blot analysis. Ovarian cancer cells were homogenized in cold NP40 buffer (Beyotime Institute of Biotechnology), protease inhibitor cocktail (Complete ${ }^{\mathrm{TM}}$, EDTA-free) and phosphatase inhibitor cocktail (PhosStop) (both from Roche Applied Science, Penzberg, Germany) and sonicated on ice, and the lysates were centrifuged at $13,684 \mathrm{x} \mathrm{g}$ for $10 \mathrm{~min}$ at $4^{\circ} \mathrm{C}$. Protein was quantified using a bicinchoninic acid assay (Beyotime Institute of Biotechnology). The protein samples were boiled in protein sample buffer for $8 \mathrm{~min}$. Then, $30 \mu \mathrm{g}$ protein per well was resolved on $10 \%$ SDS-polyacrylamide gels and transferred onto polyvinylidene fluoride membranes (GE Healthcare Life Sciences, Little Chalfont, UK). The membranes were probed with $\mathrm{H} 3 \mathrm{~K} 27 \mathrm{me} 3$ antibody $(1: 1,000)$, H3 antibody (1:5,000), EZH2 antibody (1:2,000), SUZ12 antibody (1:1,000), EED antibody $(1: 2,000), \mathrm{AMPK} \alpha$ antibody $(1: 1,000), \mathrm{p}$-AMPK $\alpha$ antibody $(1: 1,000)$, and $\beta$-actin antibody $(1: 5,000)$ for $24 \mathrm{~h}$ in $4^{\circ} \mathrm{C}$ following blocking with $5 \%$ skim milk in Tris-buffered saline and Tween-20 (TBST). Following washing in TBST the membrane was incubated with HRP anti-mouse antibody (1:5,000) or HRP anti-rabbit antibody $(1: 5,000)$ at room temperature for $1 \mathrm{~h}$. Protein bands were measured via Novex ECL HRP chemiluminescent substrate reagent (Thermo Fisher Scientific, Inc.) and scanned using Image Lab Software in Molecular Imager ${ }^{\circledR}$ ChemiDoc $^{\mathrm{TM}}$ $\mathrm{XRS}^{+}$(Bio-Rad Laboratories, Inc., Hercules, CA, USA) and normalized to internal control $\beta$-actin. All the experiments were repeated at least three times.

Statistical analysis. Data are presented as the mean \pm standard deviation. One-way analysis of variance with Tukey's post hoc tests were used for multiple comparisons between groups. $\mathrm{P}<0.05$ was considered to indicate a statistically significant difference.

\section{Results}

Metformin inhibits ovarian cancer growth and migration in vitro. To examine the effect of metformin on the aggressive progression of ovarian cancer, SKOV3, A2780 and ES2 cells cultured in hyperglycemic medium or normoglycemic medium were treated with $10 \mathrm{mM}$ metformin for $24 \mathrm{~h}$, and cell proliferation, apoptosis and migration ability were then determined. Untreated cells served as control. EdU assays demonstrated that the cell proliferation was significantly reduced by metformin under both hyperglycemic and normoglycemic conditions. Compared with the control cells, the proliferation rates in SKOV3, A2780 and ES2 cells were decreased by $6.55,38.72$ and $33.96 \%$ following metformin treatment in hyperglycemic medium, respectively. In normoglycemic medium, the proliferation rates in SKOV3, A2780 and ES2 were decreased by 9.1, 33.37 and $34.7 \%$, respectively. Intriguingly, the cell proliferation rates in the normoglycemic 
A

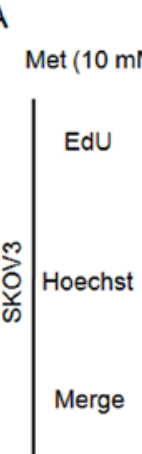
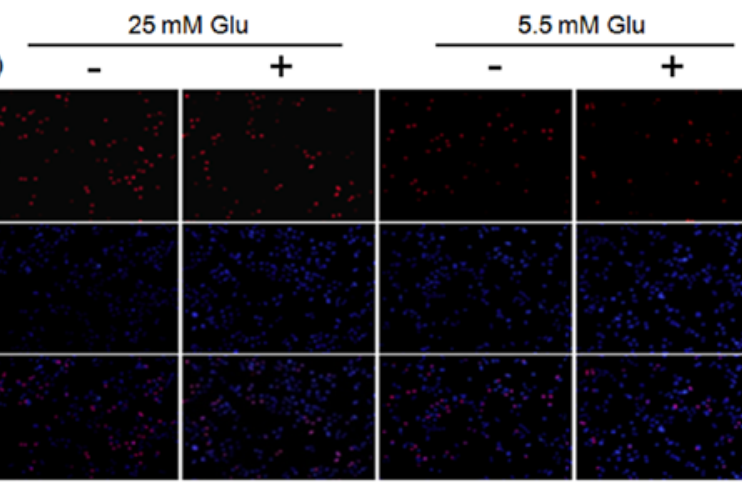

B
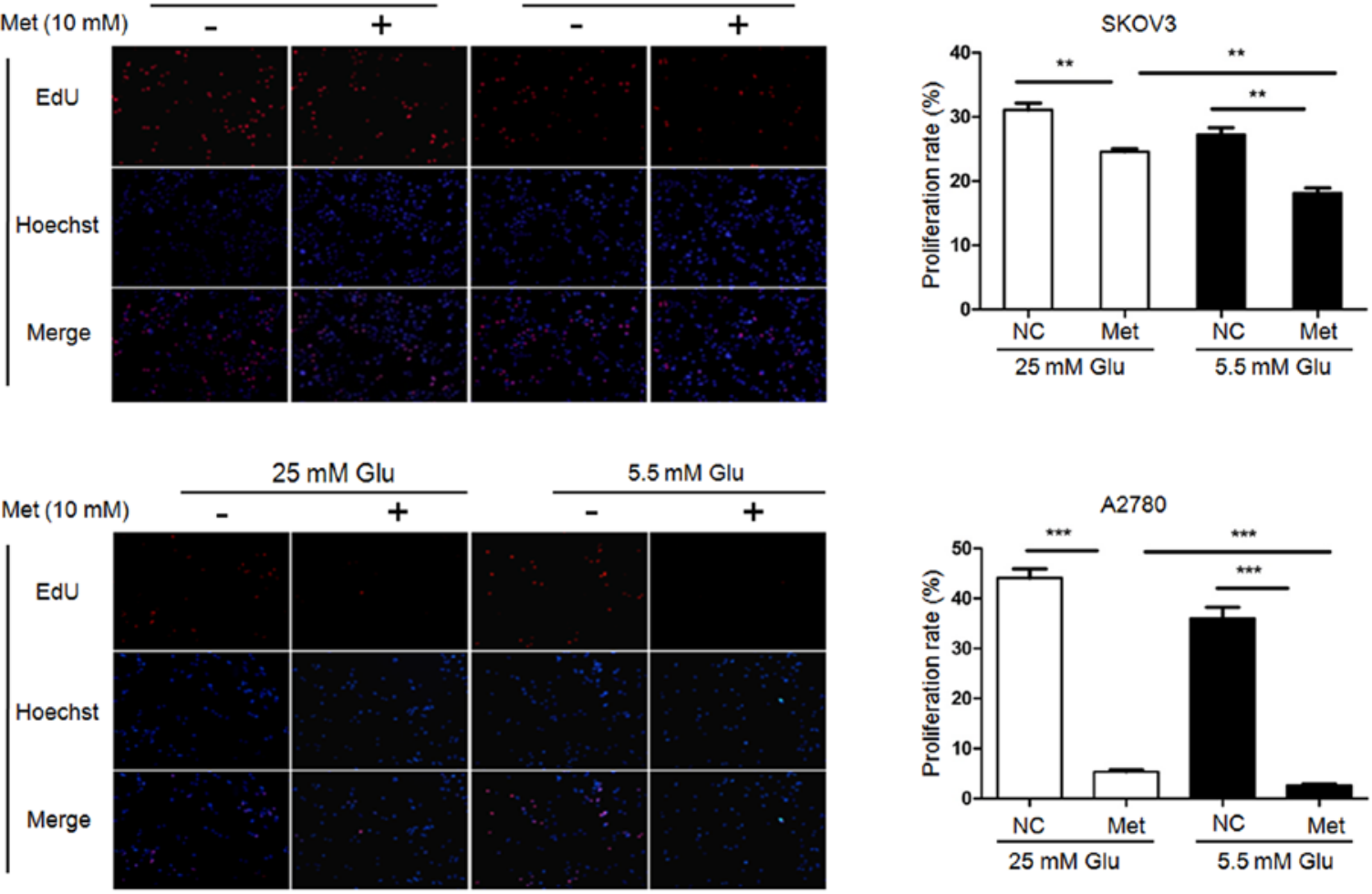

C
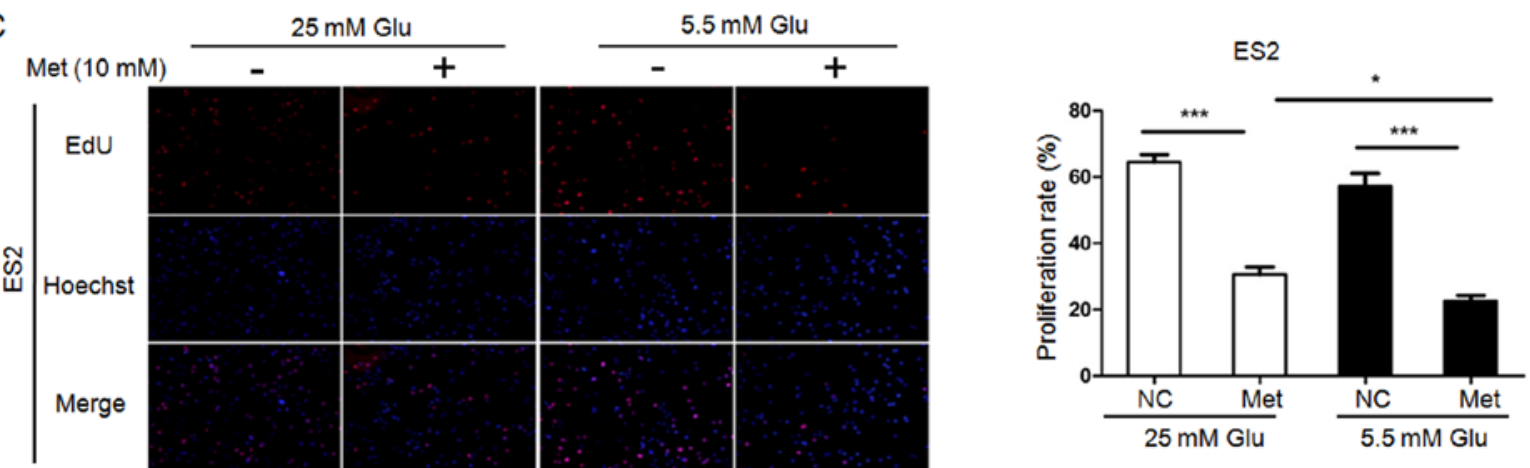

Figure 1. Metformin inhibits the proliferation of ovarian cancer cells. EdU assays demonstrate that metformin reduces proliferation of (A) SKOV3, (B) A2780 and (C) ES2 cells. Representative fluorescence microscopy images of EdU incorporation and Hoechst 33342 staining of nuclei (magnification, x100). The proliferation rates of SKOV3, A2780, and ES2 cells were calculated. Data are presented as the mean \pm standard deviation. ${ }^{*} \mathrm{P}<0.05$; ${ }^{* *} \mathrm{P}<0.01 ;{ }^{* * *} \mathrm{P}<0.001$. Met, metformin; Glu, glucose; EdU, 5-ethynyl-20-deoxyuridine; NC, negative control.

cells were significantly lower than those in the hyperglycemic cells exposure to metformin (Fig. 1).

FITC/PI flow cytometry assays demonstrated that the apoptosis rates in SKOV3 and ES2 cells were significantly increased following metformin treatment under normoglycemia, but not under hyperglycemia. Furthermore, all three ovarian cancer cell lines undergoing metformin treatment in normoglycemic condition exhibited a higher apoptosis rate compared with those treated with metformin in hyperglycemic condition (Fig. 2). Scratch wound healing assays and Transwell migration assays revealed that the migration capacity of ovarian cancer cells under hyperglycemic and normoglycemic conditions were inhibited by metformin, with more intensive inhibition under normoglycemic condition (Figs. 3 and 4). As $10 \mathrm{mM}$ metformin increases apoptosis under hypoglycaemia, it may impact the migration results. To exclude the influence of increased apoptosis on H3K27me3 and migration, ovarian cancer cells were exposed to a low metformin concentration $(2.5 \mathrm{mM})$ under normoglycemic condition. As shown in Fig. 5A and B, $2.5 \mathrm{mM}$ metformin did not enhance the cell apoptosis, while the migration and H3K27me3 level were decreased (Figs. 5C and 6A). These results suggest that metformin inhibits cell proliferation and migration, and promotes apoptosis, and that reduction of glucose concentration enhances the sensitivity of ovarian cancer cells to metformin.

Metformin inhibits H3K27me3 in ovarian cancer cells. To investigate whether $\mathrm{H} 3 \mathrm{~K} 27 \mathrm{me} 3$ has a role in the mechanism of metformin, the alterations in $\mathrm{H} 3 \mathrm{~K} 27 \mathrm{me} 3$ level and the expression of three main components of the PRC2 (i.e. EZH2, SUZ12 and EED) following metformin treatment were assessed. Ovarian cancer cells were treated with various concentrations of metformin $(0,2.5,5$ and $10 \mathrm{mM})$ in medium containing 5.5 
A

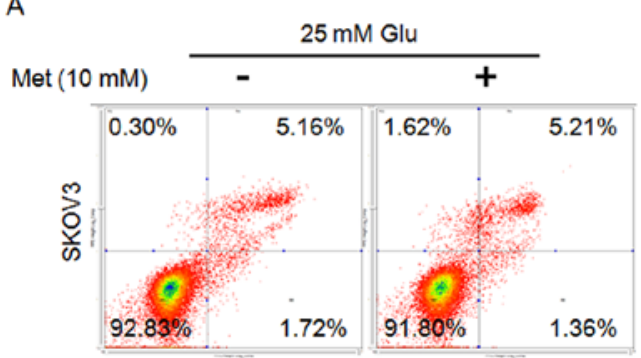

B
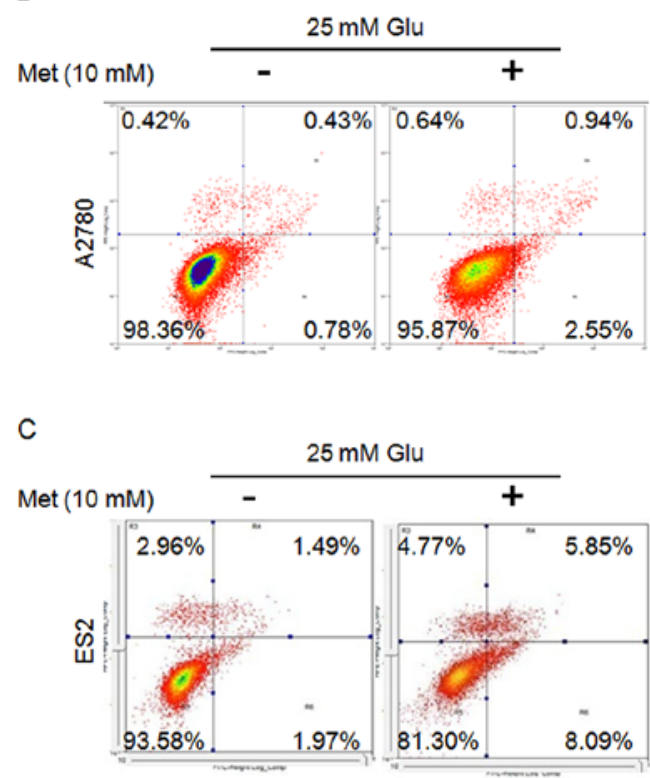
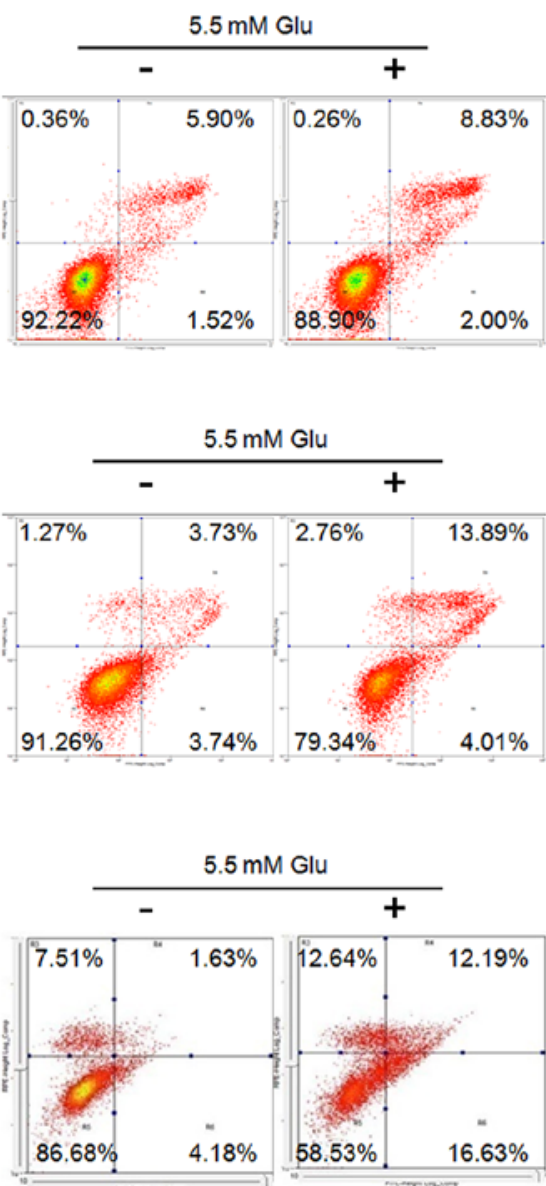

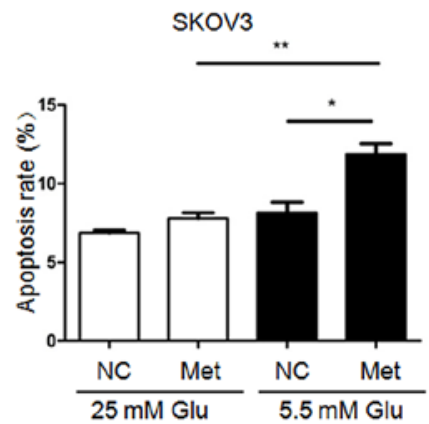

A2780
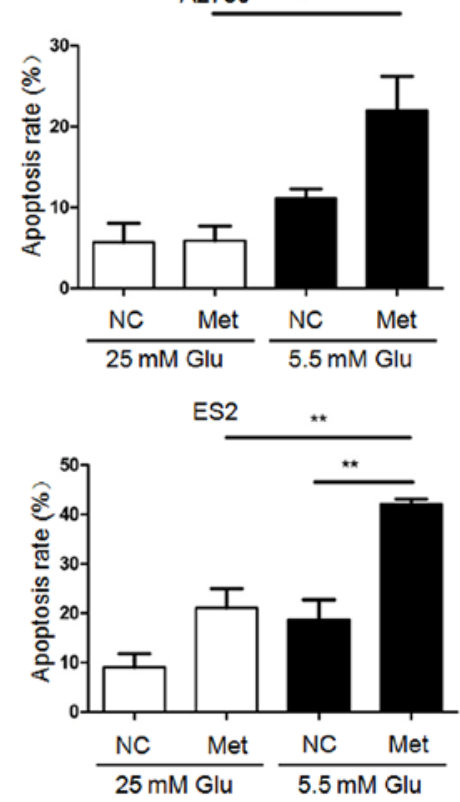

Figure 2. Metformin promotes the apoptosis of ovarian cancer cells. Percentage of apoptotic (A) SKOV3, (B) A2780 and (C) ES2 cells were detected by flow cytometry analysis using Annexin V-fluorescein isothiocyanate/PI staining. Apoptotic cells includes Annexin V(-)/PI(+), Annexin V(+)/PI(-) and Annexin V(+)/PI(+) cells. Data are presented the mean \pm standard deviation. ${ }^{*} \mathrm{P}<0.05 ;{ }^{* *} \mathrm{P}<0.01$. PI, propidium iodide; Met, metformin; Glu, glucose; NC, negative control.

or $25 \mathrm{mM}$ glucose for $24 \mathrm{~h}$. Western blot analysis demonstrated that metformin suppressed H3K27me3 level in ovarian cancer cells in a dose-dependent manner, particularly in medium with lower glucose concentration (Fig. 6A). The protein and mRNA expression of EZH2, SUZ12 and EED were decreased to varying extents following exposure to metformin under normoglycemic condition in all three cell lines, while the suppression was rather modest in the cells under hyperglycemic conditions (Figs. 6B and 7). Under hyperglycemic conditions, the protein level of SUZ12 was reduced in SKOV3 (Fig. 6B), but there was no significant inhibition in mRNA levels (Fig. 7), which may be due to post-transcriptional modifications.

Metformin inhibits ovarian cancer through decreasedH3K27me3. To demonstrate the role of H3K27me 3 in the metformin-mediated antitumor effect, H3K27me3 level was upregulated in SKOV3 and ES2 cells using an EZH2 DNA lentivirus (Fig. 8A), and cell proliferation (Fig. 8B-D), migration abilities (Fig. 9) and apoptosis (Fig. 10) were assessed. Ovarian cancer cells were treated with $10 \mathrm{mM}$ metformin in medium containing $5.5 \mathrm{mM}$ glucose under normoglycemic condition for $24 \mathrm{~h}$. Cells transfected with empty lentivirus served as the negative control. Upregulation of H3K $27 \mathrm{me} 3$ enhanced the proliferation and migration of ovarian cancer cells (Figs. 8 and 9). Compared with the cells transfected with empty lentivirus, metformin did not significantly affect the cell proliferation, apoptosis or migration of SKOV 3 and ES2 cells transfected with EZH2 lentivirus (Figs. 8-10). These results indicate that decreased $\mathrm{H} 3 \mathrm{~K} 27 \mathrm{me} 3$ is essential for the antitumor effect of metformin in ovarian cancer cells.

Metformin inhibits H3K27me3 through AMPK pathway. Given that metformin is an AMPK activator, whether metformin suppresses PRC2 through the AMPK pathway was investigated. AMPK $\alpha$ and p-AMPK $\alpha$ levels were assessed in cancer cells treated with $0,2.5,5$ and $10 \mathrm{mM}$ metformin. As shown in Fig. 11A, metformin induced phosphorylation of AMPK $\alpha$ at Thr-172 in a dose-dependent manner, the ratio of $\mathrm{p}$-AMPK $\alpha / \mathrm{AMPK} \alpha$ was dramatically increased in the ovarian cancer cells cultured in normoglycemic medium, while the increase was slight in the cells in hyperglycemic medium. These results confirmed that metformin induced the activation of AMPK in ovarian cancer cells. Another AMPK activator, 2-DG, and an AMPK inhibitor, Compound $\mathrm{C}$, were used to evaluate the effects of AMPK activation on H3K27me3 and PRC2. Similar to metformin, 2-DG increased the $\mathrm{p}$-AMPK/AMPK ratio, and repressed the expression of H3K27me3, EZH2, SUZ12 and EED (Fig. 11B). In the cells 

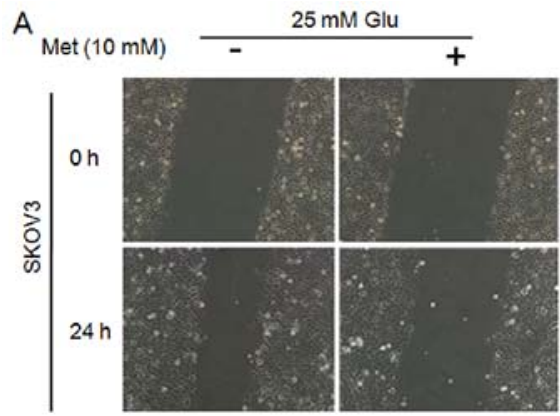

B
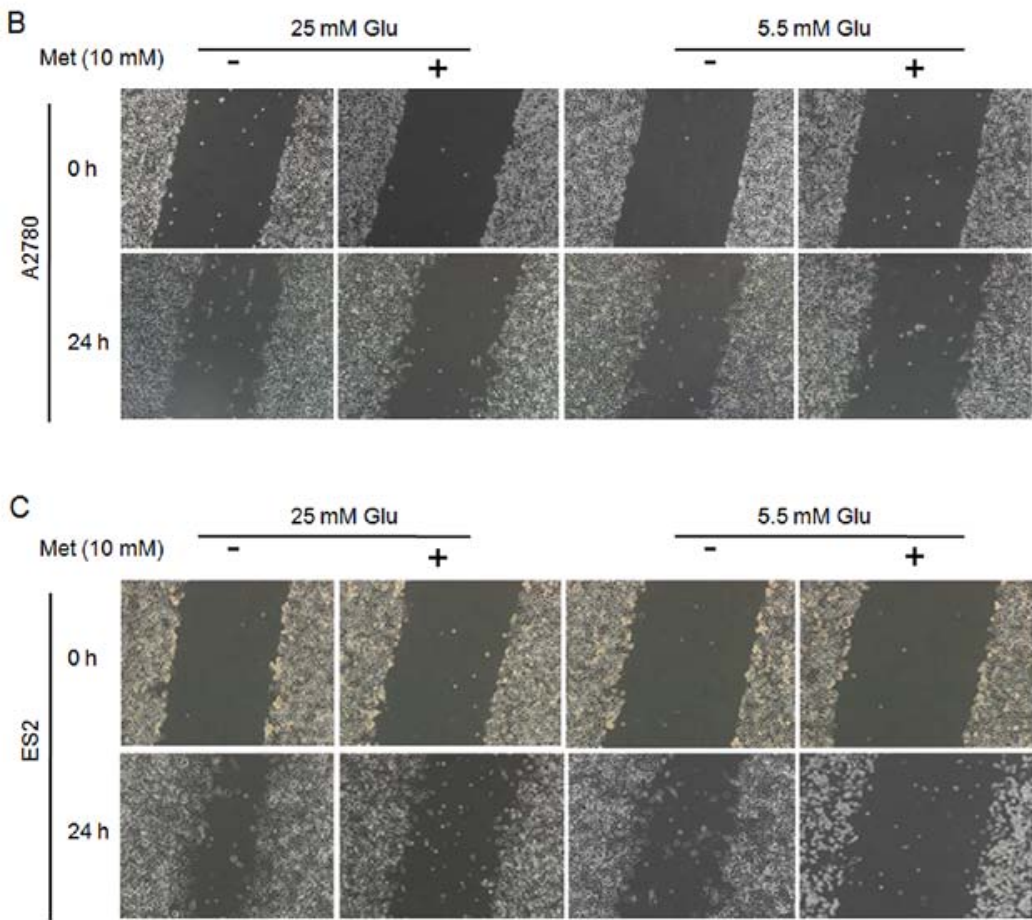

Figure 3. Metformin inhibits migration of ovarian cancer cells. Migration of (A) SKOV3, (B) A2780 and (C) ES2 cells were measured by scratch wound healing assay. Representative bright-field images (magnification, x100) and quantification of recovered distance at $24 \mathrm{~h}$ after $10 \mathrm{mM}$ metformin treatment. Data are presented the mean \pm standard deviation. ${ }^{*} \mathrm{P}<0.05 ;{ }^{* *} \mathrm{P}<0.01 ;{ }^{* * * *} \mathrm{P}<0.001$. Met, metformin; Glu, glucose; NC, negative control.

pretreated with Compound $\mathrm{C}$, metformin was not able to induce AMPK phosphorylation or inhibitEZH2, SUZ12, EED or H3K27me3 (Fig. 11C), suggesting AMPK activation is required for metformin-induced $\mathrm{PRC} 2$ inhibition.

\section{Discussion}

Multiple meta-analyses have now reported that metformin may reduce the incidence of overall cancer by $10-40 \%$, with lower risks of cancer-specific mortality (26-29). In patients with ovarian cancer, as revealed by a case-control study, metformin intake is significantly associated with improved 5-year survival (73 vs. 44\%, $\mathrm{P}=0.002$ ) (10). In mouse models, metformin inhibited the growth of ovarian cancer xenografts (5). The present study produced in vitro evidence supporting the antitumor effects of metformin in ovarian cancer and reported that H3K27me3 was abrogated by metformin through AMPK activation, which sheds new light on the underlying mechanism of metformin as an antitumor drug.

Metformin promoted cell apoptosis and repressed cell proliferation and migration in all three epithelial ovarian cancer cell lines used in the study (A2780, ES2 and SKOV3). Similar results have been reported in other epithelial ovarian cancer cell lines, including PA-1, OVCAR-3 and HO8910-PM $(30,31)$. It is well established that tumor cells can be starved by the metformin-mediated ATP depletion that confers susceptibility to cell death. In addition to regulating energy homeostasis, metformin was previously reported to alter folate metabolism, disturbing nucleotide synthesis and inhibiting cell proliferation (32). It is notable that the antitumor effects of metformin were more robust in the low glucose medium, which provides preliminary evidence supporting the use of metformin for the treatment of ovarian cancer in non-diabetic patients. In line with the findings of the current study, low glucose was previously reported to enhance the cytotoxicity of metformin in breast cancer and thyroid cancer cells $(33,34)$. Zhuang et al (35) reported that lowering glucose potentiated metformin mediated ATP depletion and cell death by reducing metformin-stimulated glycolysis in ovarian and breast cancer cells, which may partially explain the influences of glucose on metformin actions. Consistently, in the current study, AMPK was more 
A

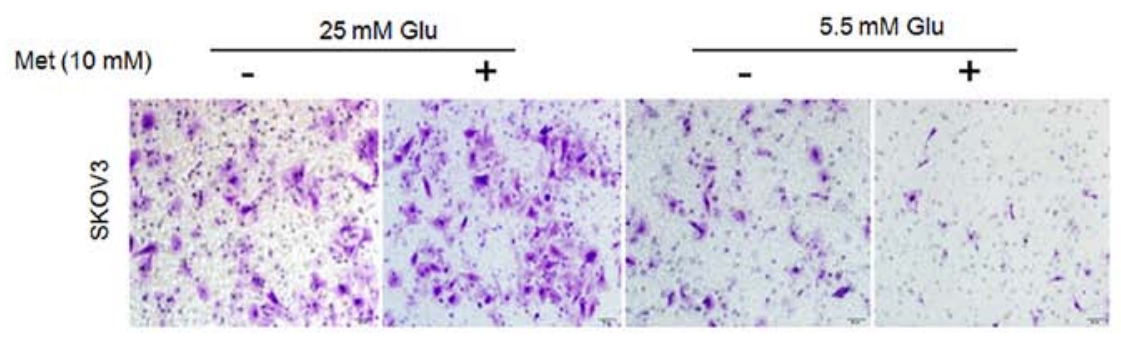

B

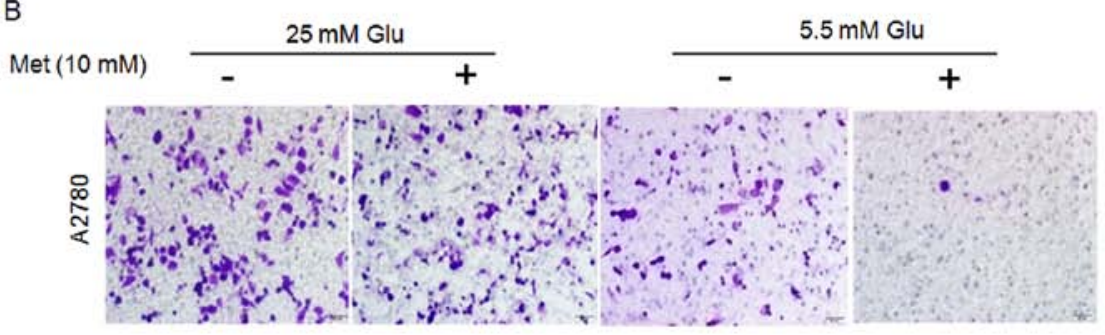

C

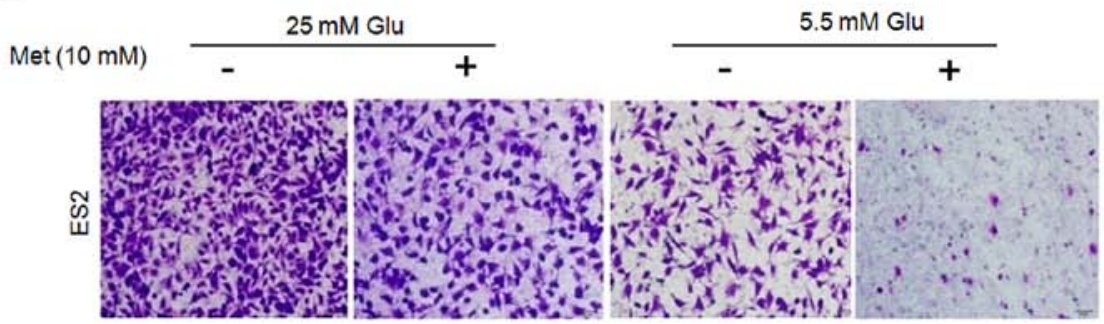

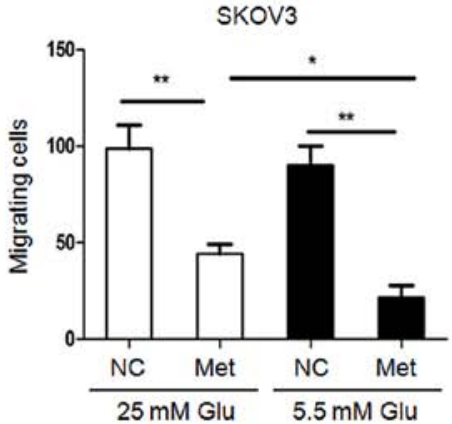
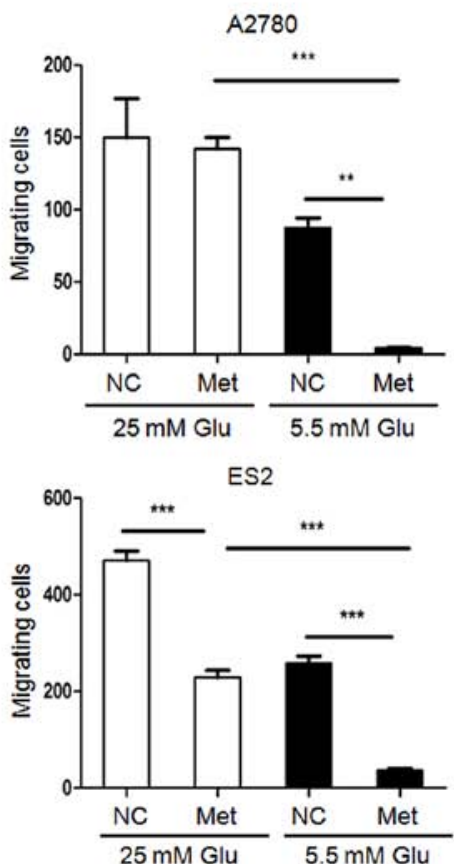

Figure 4. Metformin inhibits migration of ovarian cancer cells. Migration of (A) SKOV3, (B) A2780 and (C) ES2 cells were measured by Transwell migration assay. Representative bright-field images of the cell migration (magnification, $\mathrm{x} 100$ ) and quantification of migrated cells at $24 \mathrm{~h}$ after $10 \mathrm{mM}$ metformin treatment are shown. Data are presented the mean \pm standard deviation. ${ }^{*} \mathrm{P}<0.05 ;{ }^{* *} \mathrm{P}<0.01 ;{ }^{* * *} \mathrm{P}<0.001$. Met, metformin; Glu, glucose; NC, negative control.

strongly activated by metformin in low glucose medium, compared with high glucose medium.

The clarification of the molecular mechanisms under the antitumor effect of metformin will be of important clinical relevance regarding predicting the response to metformin therapy and selecting appropriate patients for the treatment. In the present study, metformin treatment resulted in decreasedH3K27me3 accompanied by repressed EZH2, SUZ12 and EED expression in ovarian cancer cells. The inhibition of EZH2 transcription by metformin has been previously observed in breast cancer and pancreatic cancer cells, which may be associated with re-expression of the microRNAs (miRs) targeting EZH2, including miR-26a and miR-101 $(36,37)$. In prostate cancer cells, metformin reduced the level of histone-lysine N-methyltransferase SUV39H1, a histone methyltransferase of H3 Lys9, and inhibited SUV39H1-mediated cell migration (38). These findings suggest that reduced specific histone methylation marks may mediate the antitumor effects of metformin. Further research may be warranted to investigate the presence of these histone marks on gene promoters and the consequent alterations in gene transcription in tumor cells.

AMPK is an important metabolic sensor that regulates energy homeostasis; activated AMPK induces energy sparing pathways to maintain ATP levels in response to hypoxia, fuel deprivation and low glucose level (39). As expected, in the present study, metformin-stimulated AMPK activation was dependent on the content of glucose in the environment. Notably, the metformin-induced PRC2 inhibition was rescued by pretreatment with an AMPK inhibitor (Compound C), suggesting that AMPK activation was required for the inhibitory effect of metformin on H3K27me3. Recently, Demoinet et al (40) demonstrated that AMPK is a pivotal molecular link to couple the chromatin environment and consequent adaptive changes in gene expression, and resolution of epigenetic modifications in Caenorhabditis elegans. Furthermore, AMPK inactivation was reported to be associated with enrichment of $\mathrm{H} 3 \mathrm{~K} 27 \mathrm{me} 3$ in gut epithelial cells (41). All these findings suggest cross-talking between energy stress and the methylation of histones in tumor cells.

In addition, the findings of the current study demonstrated that the decrease in $\mathrm{H} 3 \mathrm{~K} 27 \mathrm{me} 3$ is required for the antitumor effect mediated by metformin in ovarian cancer cells. $\mathrm{H} 3 \mathrm{~K} 27 \mathrm{me} 3$ contributes to $\mathrm{CpG}$ methylation in gene promoter regions and chromatin configuration, which in turn reduces the accessibility of transcription factors and the transcriptional activity of nearby genes, resulting in transcriptional 

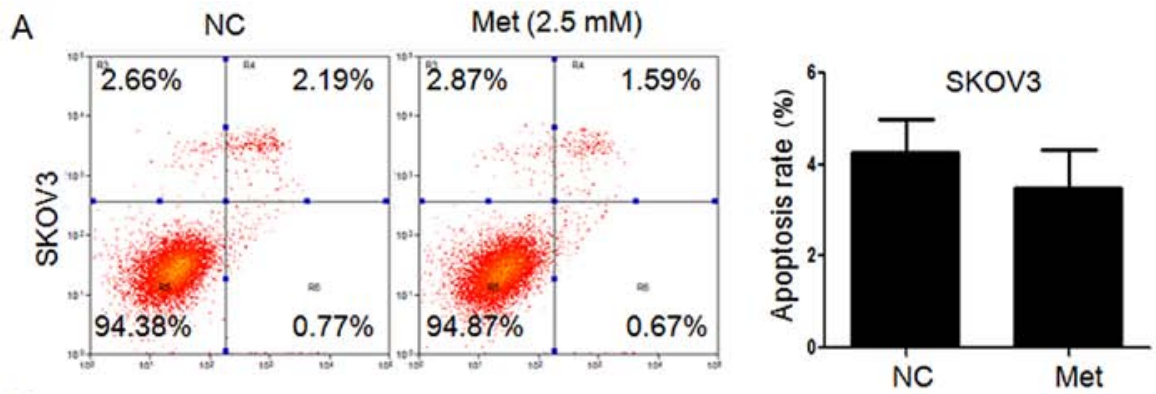

B
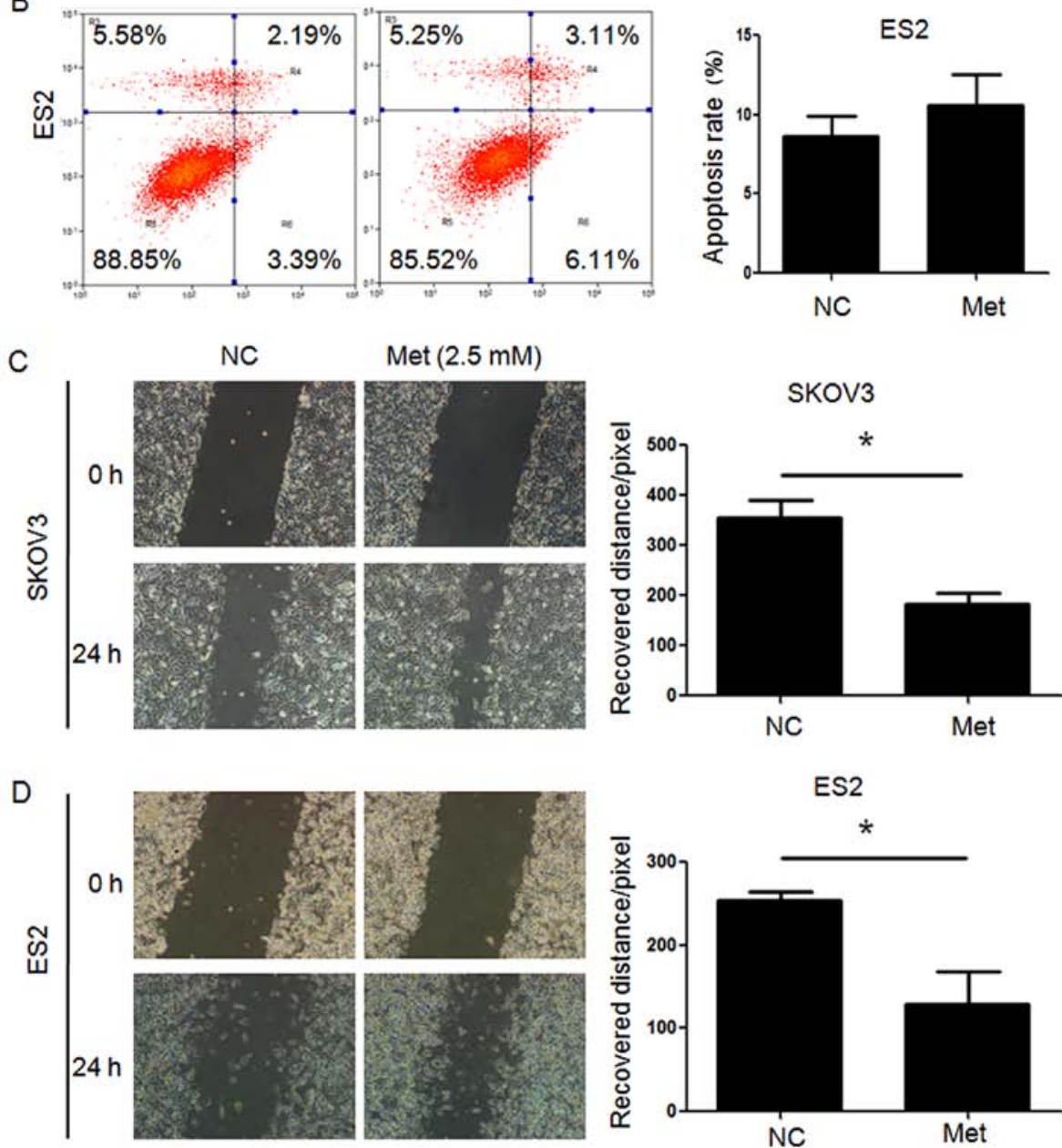

Figure 5. Metformin (2.5 mM) has no significant effect on apoptosis of ovarian cancer cells, however migration is inhibited. Percentage of apoptotic (A) SKOV3 and (B) ES2 cells were detected by flow cytometry analysis using Annexin V-fluorescein isothiocyanate/PI staining. Apoptotic cells include Annexin V(-)/PI(+), Annexin V(+)/PI(-) and Annexin V(+)/PI(+) cells. Migration of (C) SKOV3 and (D) ES2 were measured by scratch wound healing assay. Representative brightfield images (magnification, $\mathrm{x} 100$ ) and quantification of recovered distance at $24 \mathrm{~h}$ after $2.5 \mathrm{mM}$ metformin treatment. Data are presented the mean \pm standard deviation. "P<0.05. PI, propidium iodide; Met, metformin; Glu, glucose; NC, negative control.

repression. H3K 27 me3 has been reported to regulate the expression of genes involved in ovarian cancer cell proliferation, apoptosis and metastasis, such asp57, Harakiri, Aplasia Ras homolog member I and tissue inhibitor of metalloproteinase 2 (20,42-44). Notably, Zhao et al (45) demonstrated that enhancing H3K27me3 occupancy at the E3 ubiquitinprotein ligase NEDD4-likepromoter increased transforming growth factor- $\beta$ signal transduction in ovarian cancer cells, which has a critical role in tumor progression (46). These downstream mechanisms of H3K27me3 may partially explain the antitumor effects of metformin.

Taken together, the findings suggest that the antitumor effect of metformin in ovarian cancer cells may be partially attributed to the metformin-mediated AMPK activation and the consequent reduction of H3K27me3, particularly under normoglycemia condition. Several small molecular inhibitors of EZH2 are being assessed in clinical trials to treat patients with malignancies. For example, CPI-1205 and Tazemetostat are current being used in patients with B-cell lymphoma and synovial sarcoma in phase I clinical trials (NCT02395601 and NCT02601937; clinicaltrials.gov), respectively. However, it usually takes $>10$ years to take a novel drug from the laboratory to clinical use. By contrast, repurposing of metformin as an antitumor agent is a shortcut, as above all, its biological safety has been well documented. The findings of the current study indicate that metformin maybe an epigenetic regulator 
A

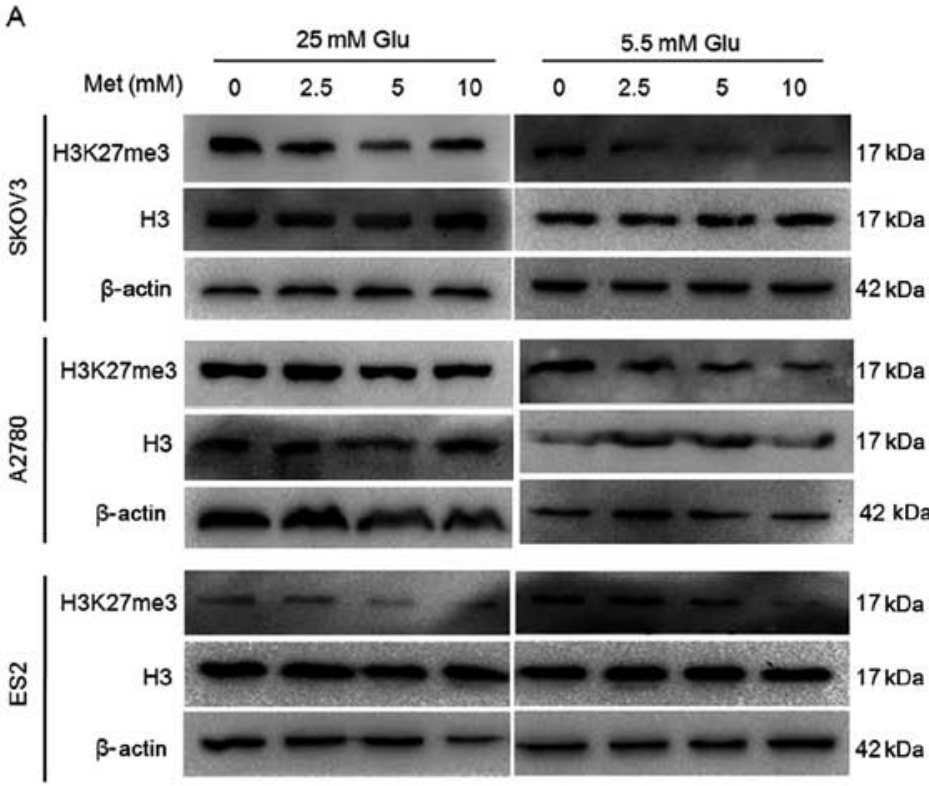

B

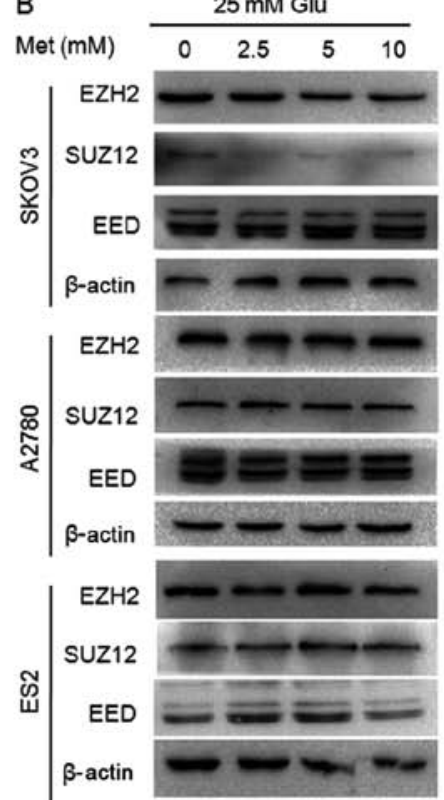

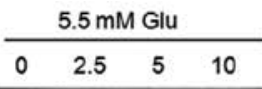

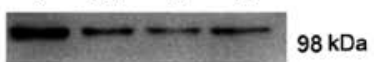

$-\frac{1}{-}-1 \mathrm{kDa}$

$= \pm 5 \mathrm{kDa}$

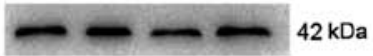

$--198 \mathrm{kDa}$

Tat- $83 \mathrm{kDa}$

$=55 \mathrm{kDa}$

$-2-12 \mathrm{kDa}$

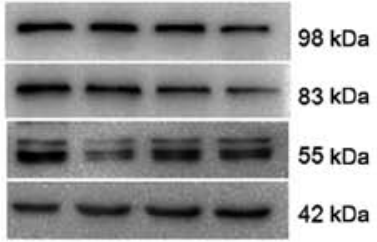

Figure 6. Metformin decreases H3K27me3 and expression of polycomb repressor complex 2 in ovarian cancer cells. The protein expression of (A) H3K27me3 and (B) EZH2, SUZ12 and EED in A2780, SKOV3 and ES2 cells were assayed by western blot analysis. Met, metformin; Glu, glucose; H3K27me3, histone $\mathrm{H} 3$ lysine 27 trimethylated; H3, histone H3; EZH2, histone-lysine N-methyltransferase EZH2; SUZ12, polycomb protein SUZ12; EED, polycomb protein EED.
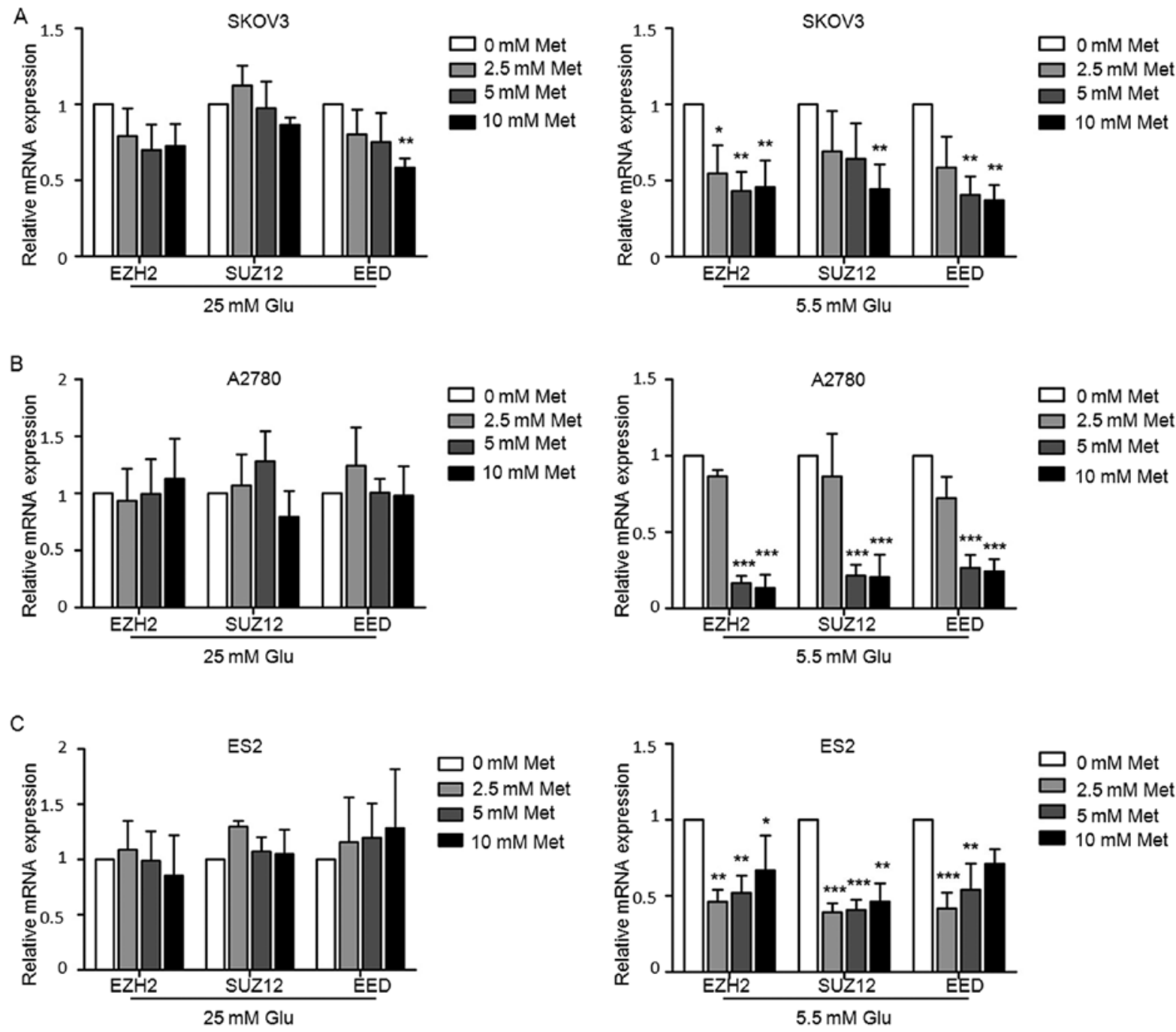

Figure 7. Metformin decreases PRC2 of ovarian cancer cells. mRNA expression of EZH2, SUZ12 and EED in (A) SKOV3, (B) A2780 and (C) ES2 cells determined by reverse transcription-quantitative polymerase chain reaction analysis. Data are presented the mean \pm standard deviation. ${ }^{*} \mathrm{P}<0.05 ;{ }^{* *} \mathrm{P}<0.01$; ${ }_{* * * *} \mathrm{P}<0.001$. Met, metformin; Glu, glucose; EZH2, histone-lysine N-methyltransferase EZH2; SUZ12, polycomb protein SUZ12; EED, polycomb protein EED. 


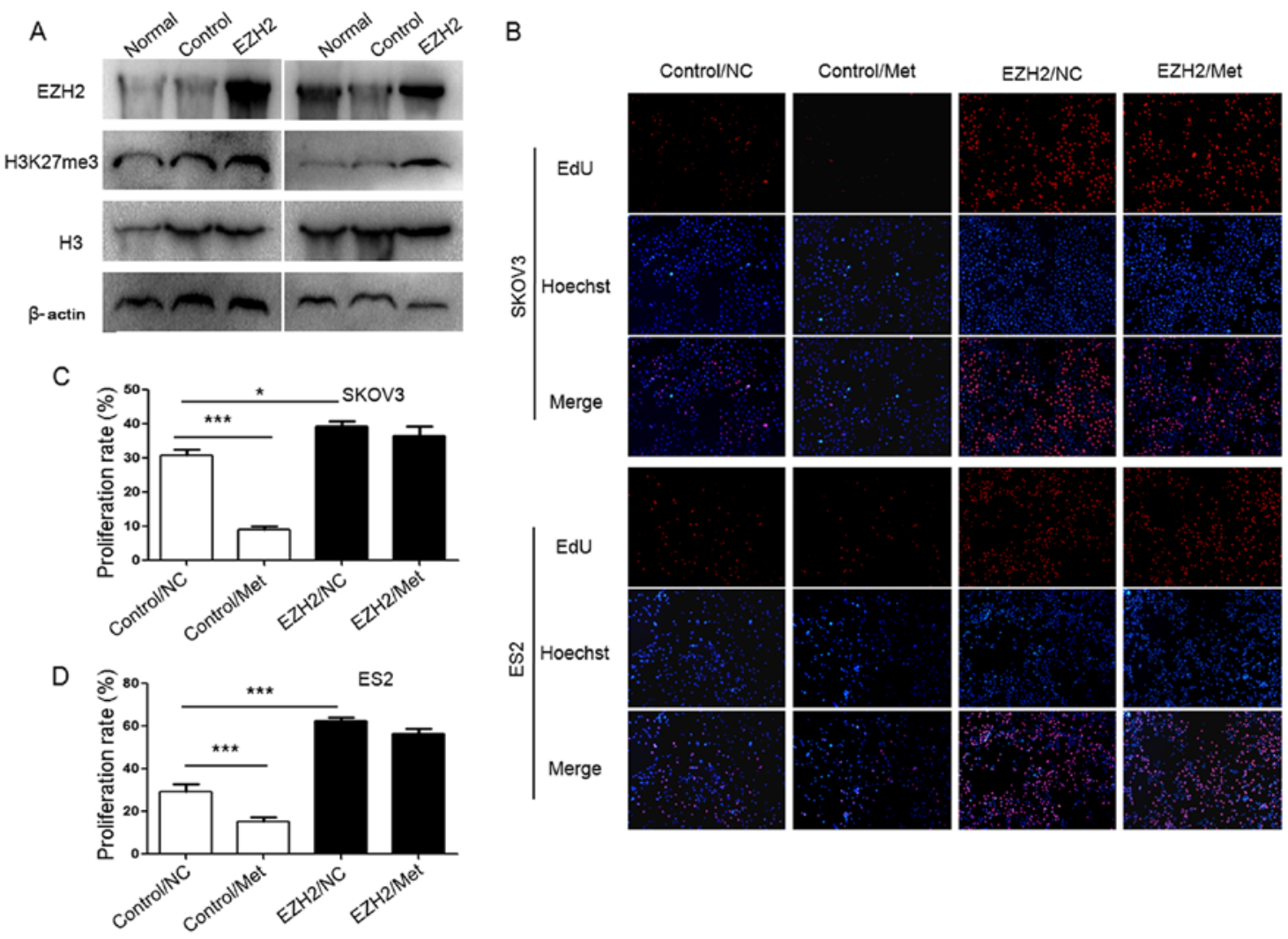

Figure 8. Overexpression of EZH2suppresses the inhibitory effect of metformin on proliferation of ovarian cancer cells. (A) EZH2 DNA lentivirus upregulated EZH2 andH3K27me3 protein expression. The protein expression of EZH2 and the level of H3K27me3 in SKOV3 and ES2 cells were assayed by western blot analysis. (B) EdU assays evaluated the proliferation of ovarian cancer cells. Representative fluorescence microscopy images of EdU incorporation and Hoechst 33342 staining of nuclei (magnification, x100). The proliferation rates of (C) SKOV3 and (D) ES2 cells. Data are presented the mean \pm standard deviation. ${ }^{*} \mathrm{P}<0.05 ;{ }^{* * *} \mathrm{P}<0.001$. EZH2, histone-lysine $\mathrm{N}$-methyltransferase EZH2; H3K27me3, histone H3 lysine 27 trimethylated; H3, histone H3; NC, negative control; Met, metformin; EdU, 5-ethynyl-20-deoxyuridine.

A
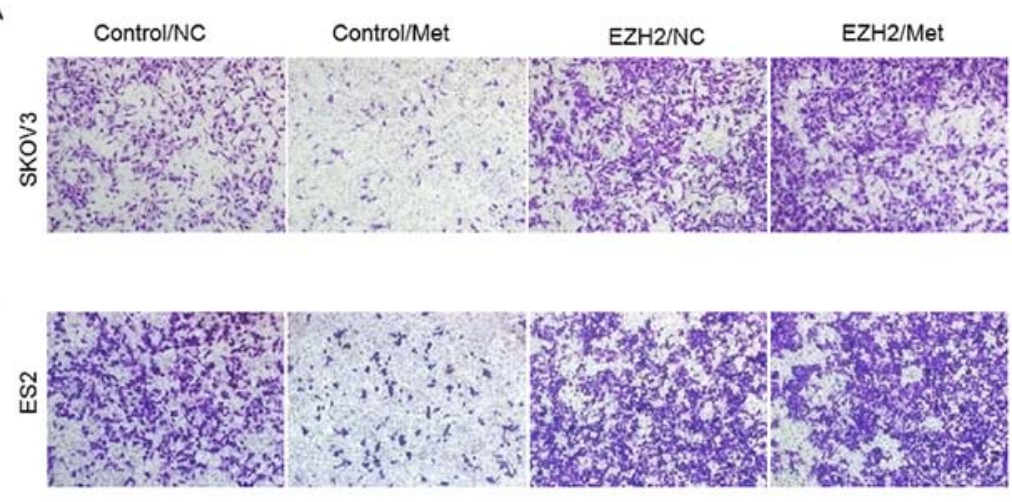

C

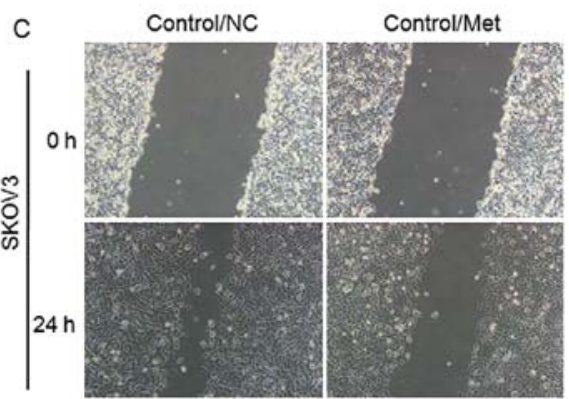

$\mathrm{EZH} 2 / \mathrm{NC}$

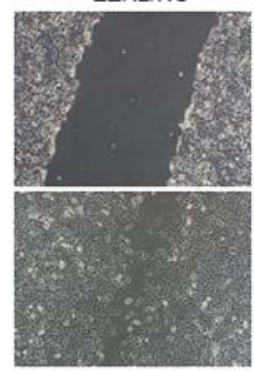

EZH2/Met

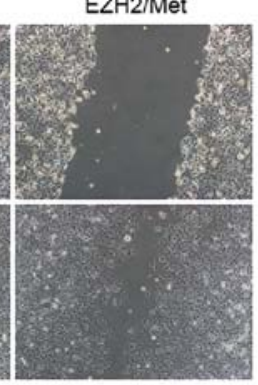

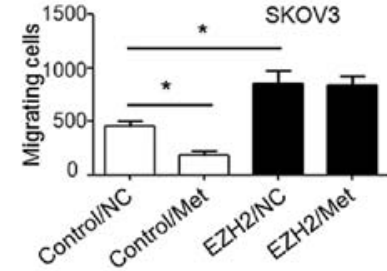
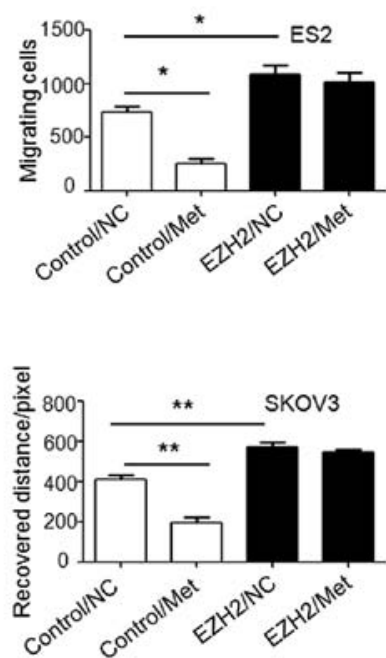

Figure 9. Overexpression of EZH2 suppresses the inhibitory effect of metformin on migration of ovarian cancer cells. Migration of (A) SKOV3 and (B) ES2 cells were measured by Transwell migration assay (crystal violet staining), and (C) a scratch wound healing assay was performed using SKOV3 cells. Representative bright-field images of the cell migration (magnification, x100) and quantification of migrated cells or recovered distance at $24 \mathrm{~h}$ after $10 \mathrm{mM}$ metformin treatment are shown. Data are presented the mean \pm standard deviation. ${ }^{*} \mathrm{P}<0.05 ;{ }^{* * *} \mathrm{P}<0.01$. NC, negative control; Met, metformin; EZH2, histone-lysine N-methyltransferase EZH2. 
A
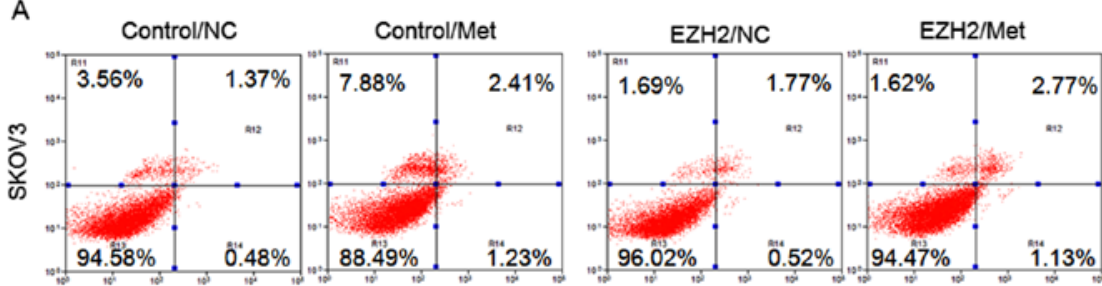

B
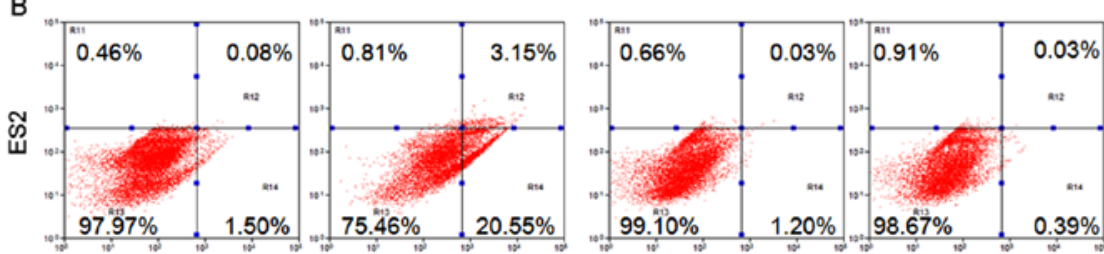
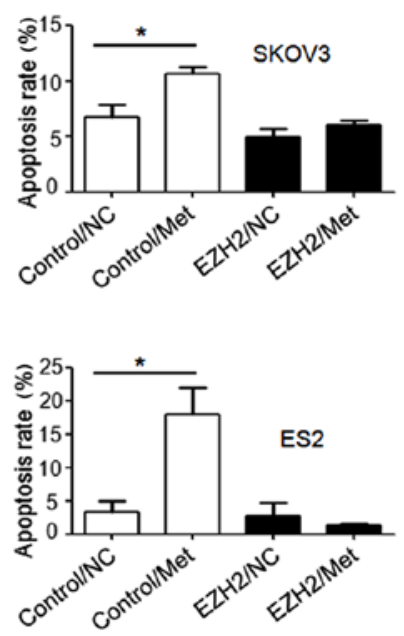

Figure 10. Overexpression of EZH2 suppresses the effect of metformin on apoptosis of ovarian cancer cells. Percentage of apoptotic (A) SKOV3 and (B) ES2 cells were detected by flow cytometry analysis using Annexin V-PE/7-AAD staining. Apoptotic cells include Annexin V(-)/7-AAD(+), Annexin V(+)/7-AAD(-) and Annexin $\mathrm{V}(+) / 7-\mathrm{AAD}(+)$ cells. Data are presented the mean \pm standard deviation. "P<0.05. PE, phycoerythrin; 7-AAD, 7-aminoactinomycin $\mathrm{D} ; \mathrm{NC}$, negative control; Met, metformin; EZH2, histone-lysine N-methyltransferase EZH2.

A

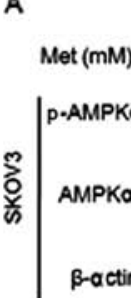
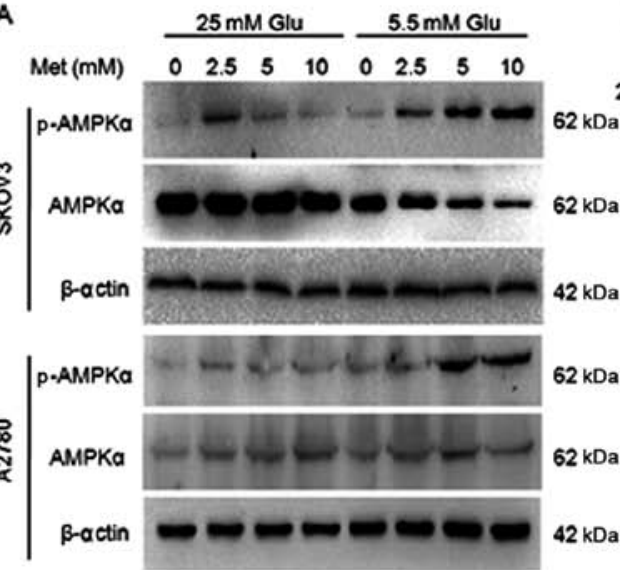

$\mid \begin{aligned} & \text { P-AMPK } \\ & \text { AMPKo } \\ & \text { B-ACtin }\end{aligned}$
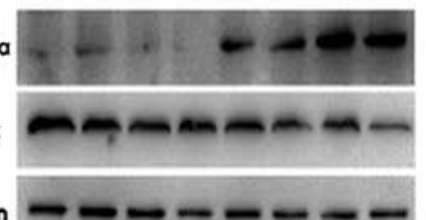

$\rightarrow--\infty-\infty-\infty$
B

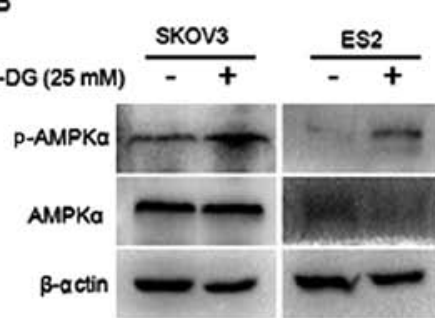

EZH2
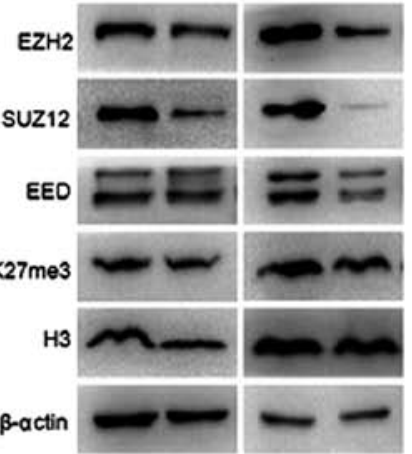

$62 \mathrm{kDa}$ H3K27me3

$62 \mathrm{kDa}$

$42 \mathrm{kDa}$

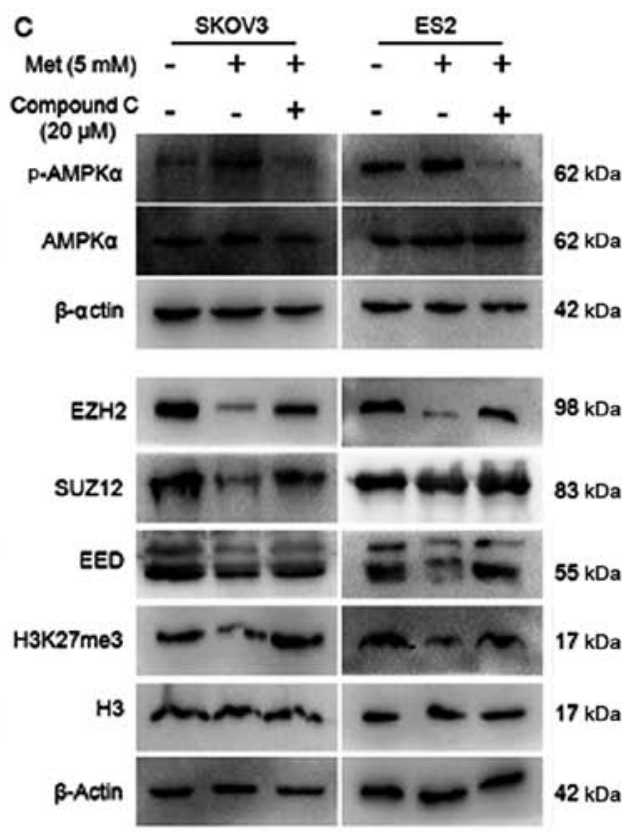

Figure 11. Metformin inhibits H3K27me3 through the AMPK pathway. (A) Metformin activates AMPK of ovarian cancer cells in normoglycemic condition. (B) 2-DG activates AMPK and suppresses H3K27me3, PRC2 of ovarian cancer cells in normoglycemic condition. (C) Compound C inhibits the effect of metformin on PRC2 and H3K27me3 when ovarian cancer cells were cultured in normoglycemic condition. The protein expression of p-AMPK $\alpha, \mathrm{AMPK} \alpha, \mathrm{H} 3 \mathrm{~K} 27 \mathrm{me} 3$, EZH2, SUZ12 and EED in A2780, SKOV3 and ES2 cells were assayed by western blot analysis. The expression was normalized to $\beta$-actin. Met, metformin; Glu, glucose; p-AMPK $\alpha$, phospho-AMPK $\alpha$; AMPK $\alpha$, AMP-activated protein kinase; 2-DG, 2-deoxy-D-glucose; EZH2, histone-lysine N-methyltransferase EZH2;SUZ12, polycomb protein SUZ12; EED, polycomb protein EED; 2-DG, dorsomorphin 2HCl; H3K27me3, histone H3 lysine 27 trimethylation.

targeting PRC2 and support the use of metformin in treatment of patients with epithelial ovarian cancer without diabetes.

\section{Acknowledgements}

Not applicable.

\section{Funding}

This study was supported by the National Science Foundation of China (grant nos. 81672573, 81472443 and 81372807).

\section{Availability of data and materials}

The data sets generated during the current study are available from the corresponding author on reasonable request.

\section{Authors' contributions}

ZW, JG and JC contributed to the conception and design; GT, YZ and TL contributed to acquisition of data; GT, ZH and LY contributed to analysis and interpretation of data for the work; all authors drafted the work and revised it critically for 
important intellectual content; all authors approved the final manuscript to be published; all authors agree to be accountable for all aspects of the work in ensuring that questions related to the accuracy or integrity of any part of the work are appropriately investigated and resolved.

\section{Ethics approval and consent to participate}

Not applicable.

\section{Consent for publication}

Not applicable.

\section{Competing interests}

The authors declare that they have no competing interests.

\section{References}

1. Siegel RL, Miller KD and Jemal A: Cancer statistics, 2016. CA Cancer J Clin 66: 7-30, 2016

2. Davis A, Tinker AV and Friedlander M: 'Platinum resistant' ovarian cancer: What is it, who to treat and how to measure benefit? Gynecol Oncol 133: 624-631, 2014.

3. Coyle C, Cafferty FH, Vale C and Langley RE: Metformin as an adjuvant treatment for cancer: A systematic review and metaanalysis. Ann Oncol 27: 2184-2195, 2016.

4. Dowling RJ, Niraula S, Chang MC, Done SJ, Ennis M, McCready DR, Leong WL, Escallon JM, Reedijk M, Goodwin PJ, et al: Changes in insulin receptor signaling underlie neoadjuvant metformin administration in breast cancer: A prospective window of opportunity neoadjuvant study. Breast Cancer Res 17: 32, 2015.

5. Rattan R, Graham RP, Maguire JL, Giri S and Shridhar V: Metformin suppresses ovarian cancer growth and metastasis with enhancement of cisplatin cytotoxicity in vivo. Neoplasia 13 : 483-491, 2011.

6. Blandino G, Valerio M, Cioce M, Mori F, Casadei L, Pulito C, Sacconi A, Biagioni F, Cortese G, Galanti S, et al: Metformin elicits anticancer effects through the sequential modulation of DICER and c-MYC. Nat Commun 3: 865, 2012.

7. Sivalingam VN, Kitson S, McVey R, Roberts C, Pemberton P, Gilmour K, Ali S, Renehan AG, Kitchener HC and Crosbie EJ: Measuring the biological effect of presurgical metformin treatment in endometrial cancer. Br J Cancer 114: 281-289, 2016

8. Currie CJ, Poole CD, Jenkins-Jones S, Gale EAM, Johnson JA and Morgan CL: Mortality after incident cancer in people with and without type 2 diabetes: Impact of metformin on survival Diabetes Care 35: 299-304, 2012.

9. Romero IL, McCormick A, McEwen KA, Park S, Karrison T, Yamada SD, Pannain S and Lengyel E: Relationship of type II diabetes and metformin use to ovarian cancer progression, survival, and chemosensitivity. Obstet Gynecol 119: 61-67, 2012.

10. Kumar S, Meuter A, Thapa P, Langstraat C, Giri S, Chien J, Rattan R, Cliby W and Shridhar V: Metformin intake is associated with better survival in ovarian cancer: A case-control study. Cancer 119: 555-562, 2013.

11. Jenkins Y, Sun TQ, Markovtsov V, Foretz M, Li W, Nguyen H, Li Y, Pan A, Uy G, Gross L, et al: AMPK activation through mitochondrial regulation results in increased substrate oxidation and improved metabolic parameters in models of diabetes. PLoS One 8: e81870, 2013.

12. Han G, Gong H, Wang Y,GuoS andLiu K: AMPK/mTOR-mediated inhibition of survivin partly contributes to metformin-induced apoptosis in human gastric cancer cell. Cancer Biol Ther 16: 77-87, 2015.

13. Ochoa-GonzalezF, Cervantes-Villagrana AR, Fernandez-Ruiz JC, Nava-Ramirez HS, Hernandez-Correa AC, Enciso-Moreno JA and Castañeda-Delgado JE: Metformin induces cell cycle arrest, reduced proliferation, wound healing impairment in vivo and is associated to clinical outcomes in diabetic foot ulcer patients. PLoS One 11: e0150900, 2016.
14. Pollak M: The insulin and insulin-like growth factor receptor family in neoplasia: An update. Nat Rev Cancer 12: 159-169, 2012.

15. Portela A and Esteller M: Epigenetic modifications and human disease. Nat Biotechnol 28: 1057-1068, 2010.

16. Chan KM, Fang D, Gan H, Hashizume R, Yu C, Schroeder M, Gupta N, Mueller S, James CD, Jenkins R, et al: The histone H3.3K27M mutation in pediatric glioma reprograms H3K27 methylation and gene expression. Genes Dev 27: 985-990, 2013.

17. Peng D, Kryczek I, Nagarsheth N, Zhao L, Wei S, Wang W, Sun Y, Zhao E, Vatan L, Szeliga W, et al: Epigenetic silencing of TH1-type chemokines shapes tumour immunity and immunotherapy. Nature 527: 249-253, 2015.

18. Chapman-Rothe N, Curry E, Zeller C, Liber D, Stronach E, Gabra H, Ghaem-MaghamiS and Brown R: Chromatin H3K27me3/ $\mathrm{H} 3 \mathrm{~K} 4 \mathrm{me} 3$ histone marks define gene sets in high-grade serous ovarian cancer that distinguish malignant, tumour-sustaining and chemo-resistant ovarian tumour cells. Oncogene 32: 4586-4592, 2013.

19. Cao R and Zhang Y: The functions of $\mathrm{E}(\mathrm{Z}) / \mathrm{EZH} 2$-mediated methylation of lysine 27 in histone H3. Curr Opin Genet Dev 14: $155-164,2004$.

20. Yi X, Guo J, Guo J, Sun S, Yang P, Wang J, Li Y, Xie L, Cai J and Wang Z: EZH2-mediated epigenetic silencing of TIMP2 promotes ovarian cancer migration and invasion. Sci Rep 7: 3568, 2017.

21. Hu S, Yu L, Li Z, Shen Y, Wang J, Cai J, Xiao L and Wang Z: Overexpression of EZH2 contributes to acquired cisplatin resistance in ovarian cancer cells in vitro and in vivo. Cancer Biol Ther 10: 788-795, 2010.

22. Siddiqi FS, Majumder S, Thai K, Abdalla M, Hu P, Advani SL, White KE, Bowskill BB, Guarna G, Dos Santos CC, et al: The histone methyltransferase enzyme enhancer of zeste homolog 2 protects against podocyte oxidative stress and renal injury in diabetes. J Am Soc Nephrol 27: 2021-2034, 2016.

23. Gallagher KA, Joshi A, Carson WF, Schaller M, Allen R, Mukerjee S, Kittan N, Feldman EL, Henke PK, Hogaboam C, et al: Epigenetic changes in bone marrow progenitor cells influence the inflammatory phenotype and alter wound healing in type 2 diabetes. Diabetes 64: 1420-1430, 2015.

24. Litchfield LM, Mukherjee A, Eckert MA, Johnson A, Mills KA, Pan S, Shridhar V, Lengyel E and Romero IL: Hyperglycemiainduced metabolic compensation inhibits metformin sensitivity in ovarian cancer. Oncotarget 6: 23548-23560, 2015.

25. Livak KJ and Schmittgen TD: Analysis of relative gene expression data using real-time quantitative PCR and the 2(-Delta Delta C(T)) method. Methods 25: 402-408, 2001.

26. Wu L, Zhu J, Prokop LJ and Murad MH: Pharmacologic therapy of diabetes and overall cancer risk and mortality: A meta-analysis of 265 studies. Sci Rep 5: 10147, 2015.

27. Gandini S, Puntoni M, Heckman-Stoddard BM, Dunn BK, Ford L, DeCensi A and Szabo E: Metformin and cancer risk and mortality: A systematic review and meta-analysis taking into account biases and confounders. Cancer Prev Res (Phila) 7: 867-885, 2014.

28. Zhang P,LiH, Tan X, Chen L and Wang S: Association of metformin use with cancer incidence and mortality: A meta-analysis. Cancer Epidemiol 37: 207-218, 2013.

29. Zhang ZJ and Li S: The prognostic value of metformin for cancer patients with concurrent diabetes: A systematic review and meta-analysis. Diabetes Obes Metab 16: 707-710, 2014.

30. Moon HS, Kim B, Gwak H, Suh DH and Song YS: Autophagy and protein kinase RNA-like endoplasmic reticulum kinase $($ PERK)/eukaryotic initiation factor 2 alpha kinase (eIF2 $\alpha$ ) pathway protect ovarian cancer cells from metformin-induced apoptosis. Mol Carcinog 55: 346-356, 2016.

31. Milewicz T, Kiałka M, Mrozińska S, Ociepka A and Krzysiek J: Metformin - new treatment strategies for gynecologic neoplasms. Przegl Lek 70: 81-84, 2013 (In Polish).

32. Jara JA and López-Muñoz R: Metformin and cancer: Between the bioenergetic disturbances and the antifolate activity. Pharmacol Res 101: 102-108, 2015.

33. Menendez JA, Oliveras-Ferraros C, Cufí S, Corominas-Faja B, Joven J, Martin-Castillo B and Vazquez-Martin A: Metformin is synthetically lethal with glucose withdrawal in cancer cells. Cell Cycle 11: 2782-2792, 2012.

34. Bikas A, Jensen K, Patel A, Costello J Jr, McDaniel D, KluboGwiezdzinska J, Larin O, Hoperia V, Burman KD, Boyle L, et al: Glucose-deprivation increases thyroid cancer cells sensitivity to metformin. Endocr Relat Cancer 22: 919-932, 2015. 
35. Zhuang Y, Chan DK, Haugrud AB and Miskimins WK Mechanisms by which low glucose enhances the cytotoxicity of metformin to cancer cells both in vitro and in vivo. PLoS One 9: e108444, 2014

36. Bao B, Wang Z, Ali S, Ahmad A, Azmi AS, Sarkar SH, Banerjee S, Kong D, Li Y, Thakur S, et al: Metformin inhibits cell proliferation, migration and invasion by attenuating CSC function mediated by deregulating miRNAs in pancreatic cancer cells. Cancer Prev Res (Phila) 5: 355-364, 2012.

37. Cabello P, Pineda B, Tormo E, Lluch A and Eroles P: The antitumor effect of metformin is mediated by miR-26a in breast cancer. Int J Mol Sci 17: 1298, 2016.

38. Yu T, Wang C, Yang J, Guo Y, Wu Y and Li X: Metformin inhibits SUV39H1-mediated migration of prostate cancer cells. Oncogenesis 6: e324, 2017.

39. Bonini MG and Gantner BN: The multifaceted activities of AMPK in tumor progression - why the 'one size fits all' definition does not fit at all? IUBMB Life 65: 889-896, 2013.

40. Demoinet E, Li S and Roy R: AMPK blocks starvation-inducible transgenerational defects in Caenorhabditis elegans. Proc Nat Acad Sci USA 114: E2689-E2698, 2017.

41. Sun X, Yang Q, Rogers CJ, Du M and Zhu MJ: AMPK improves gut epithelial differentiation and barrier function via regulating Cdx2 expression. Cell Death Differ 24: 819-831, 2017.
42. Fu Y, Chen J, Pang B, Li C, Zhao J and Shen K: EZH2-induced $\mathrm{H} 3 \mathrm{~K} 27 \mathrm{me} 3$ is associated with epigenetic repression of the ARHI tumor-suppressor gene in ovarian cancer. Cell Biochem Biophys 71: 105-112, 2015.

43. Li H, Cai Q, Wu H, Vathipadiekal V, Dobbin ZC, Li T, Hua X, Landen CN, Birrer MJ, Sánchez-Beato M, et al: SUZ12 promotes human epithelial ovarian cancer by suppressing apoptosis via silencing HRK. Mol Cancer Res 10: 1462-1472, 2012.

44. Guo J, Cai J, Yu L, Tang H, Chen C and Wang Z: EZH2 regulates expression of p57 and contributes to progression of ovarian cancer in vitro and in vivo. Cancer Sci 102: 530-539, 2011

45. Zhao R, Cui T, Han C, Zhang X, He J, Srivastava AK, Yu J, Wani AA and Wang QE: DDB2 modulates TGF- $\beta$ signal transduction in human ovarian cancer cells by downregulating NEDD4L. Nucleic Acids Res 43: 7838-7849, 2015.

46. Principe DR, Doll JA, Bauer J, Jung B, Munshi HG, Bartholin L, Pasche B, Lee C and Grippo PJ: TGF- $\beta$ : Duality of function between tumor prevention and carcinogenesis. J Natl Cancer Inst 106: djt369, 2014.

(i) (8) This work is licensed under a Creative Common

EY NG NO Attribution-NonCommercial-NoDerivatives 4.0 International (CC BY-NC-ND 4.0) License. 